\title{
HEADACHE FOLLOWING EPIDURAL ANAESTHESIA FOR OBSTETRICAL DELIVERY: A CASE REPORT
}

\author{
Christopher E. Famewo
}

\section{INTRODUCTION}

Epidural anAlgesia is widely used in Canada for obstetrical labour and delivery. Headache is not a complication of this technique except when associated with accidental dural puncture. The acute onset of a headache starting in the postpartum period should stimulate a search for other causes of the headache, when dural puncture has not occurred.

This case report is an example of acute onset headache in the early post-partum period following a continuous epidural block. The headache was wrongly assumed to result from the epidural procedure and was not further investigated until much later. The patient subsequently died and an autopsy indicated the cause of death to be intracerebral and intraventricular hemorrhage.

\section{Case Report}

The patient was a 26-year-old negro who was admitted in labour at full term.

She had two previous pregnancies and two deliveries. Her past medical history was uneventful. The patient denied any history of headache. Physical examination was that of a normal full-term pregnant female. Blood pressure was $130 / 80 \mathrm{~mm} \mathrm{Hg}$ and pulse rate $76 / \mathrm{min}$.

The obstetrician requested continuous epidural analgesia during the first stage of labour, and an epidural catheter was successfully inserted at the interspace between the third and fourth lumbar spines. There was no cerebrospinal fluid (CSF) leak to indicate dural puncture. An initial dose of $7 \mathrm{ml}$ of 2 per cent mepivacaine (Carbocaine ${ }^{\mathbb{1}}$ ) was injected through the epidural catheter and gave good analgesia; $5 \mathrm{ml}$ of 2 per cent mepivacaine was injected 30 minutes later to supplement analgesia and a further $10 \mathrm{ml}$ was given 15 minutes after the second dose, for delivery. The patient had an uncomplicated delivery of a baby girl with an Apgar score of nine at five minutes.

\section{Post Partum}

Day 1: About two hours post-partum the patient first complained of a severe frontal headache. Blood pressure taken at that time as part of the vital signs was elevated to $190 / 105 \mathrm{~mm} \mathrm{Hg}$. The headache was assumed to be due to the epidural anaesthesia and the patient was treated with analgesics.

Department of Anaesthesia, St. Michael's Hospital and University of Toronto, Toronto, Ontario, Canada. 
Days 2 \&: The patient continued to complain of recurring severe frontal and occipital headaches. Blood pressures taken at these times were also elevated. She continued to be treated with analgesics including aspirin, codeine and meperidine as well as with diazepam. There was very little relief.

Day 4: The patient did not complain much of headaches.

Days 5 \& 6: The patient had more episodes of headaches, hysteria and projectile vomiting. A neurologist was consulted and he similarly held the view of a low $\mathrm{CSF}$ pressure headache as a result of the epidural anaesthesia. He advised adequate hydration, nursing in the horizontal position and analgesics.

Days 7 \& 8: The patient continued to have headaches, occasional vomiting and developed some signs of meningeal irritation. The vomiting was assumed to be due to the analgesics.

Day 9: The patient developed a low grade fever (temperature $38^{\circ} \mathrm{C}$ ) and with the recent onset of meningeal irritation, the neurologist suggested a lumbar puncture to exclude an infective cause. A lumbar puncture was done and the opening pressure was $260 \mathrm{~mm} \mathrm{H}_{2} \mathrm{O}$.

The CSF was grossly bloody. At this point the working diagnosis was changed from spinal headache to subarachnoid haemorrhage. An emergency bilateral carotid angiogram was done and showed general spasm of the intracerebral vessels, hydrocephalus and questionable bilateral small Huebner's aneurysms (from the proximal parts of the anterior cerebrals). Apresoline was added to the patient's medication to control the hypertensive episodes.

Day 10: The patient had a left brachial arteriogram which showed spasm of the vertebro-basilar system.

Day 11: The patients condition further deteriorated and she became decerebrate. Emergency burr holes for insertion of Scott Cannula into the brain ventricle was done. The CSF was bloody and the pressure elevated. Tracheotomy was also done. The patient died the same day.

\section{Discussion}

Headache is not associated with epidural anaesthesia unless accidental dural puncture occurs. Our review reported an incidence of 2.5 per cent (out of 43,000 cases) of accidental dural puncture. ${ }^{1}$ The aetiology of the spinal headache is thought to be due to a low CSF pressure resulting from acute loss of CSF during the dural puncture or a slower leak subsequently through the hole in the dura. The low CSF pressure results in traction on the pain sensitive intracranial contents such as the venous sinuses and their tributaries, parts of the dura at the base of the brain, intracerebral and dural arteries, some cranial nerves (e.g., V, VI, VII, IX, X) and the cervical nerves (C 1-3). The brain parenchyma itself is insensitive to pain. ${ }^{1,2,4}$ Post-partum fatients may be more predisposed to developing spinal headache following dural puncture because the straining during labour may cause more CSF leakage. Spinal headache is usually bi-frontal or suboccipital. The onset may be as early as a few hours or may be delayed for some days. It is aggravated in the upright position and partly relieved in the horizontal position. Other associated features include nausea and vomiting, tinnitus and deafness (due to de- 
creased intralabyrinthine pressure), and diplopia (due to 6 th or 3 rd cranial nerve palsy).

The clinical picture of ruptured intracranial aneurysm is a sudden onset of violent headache which may be associated with confusion or collapse, without prodromal signs or many lateralizing signs. ${ }^{4} \mathrm{~A}$ lumbar puncture usually reveals an elevated CSF pressure, bloody CSF and increased WBC $(15,-18,00 / \mathrm{cmm})$. Subsequently neck stiffness and other signs of meningeal irritation are manifest. This patient's presentation was similar. The anaesthetist should have been informed early in the case when spinal headache was considered, to ascertain if dural puncture had occurred during the epidural technique. If there was no dural puncture the a lumbar puncture could have been done earlier for purpose of diagnosis (CSF pressure and analysis).

In this patient lumbar puncture revealed a bloody CSF and elevated CSF pressure. Subsequent autopsy showed intracerebral and intraventricular hemorrhage arising from the lenticular nucleus. No aneurysm or congenital malformations were demonstrated. Histologically, there was cerebral thrombophlebitis of unknown etiology. It is unlikely that the course of events would have been any different in this case but a correct diagnosis could have been made earlier. An early diagnosis could change the prognosis in other patients presenting similarly. The message here is that the anaesthetist should be consulted early on any suspected "spinal headache" following epidural anaesthesia technique to discuss the likelihood of dural puncture and, if it be a "spinal headache," for further management when conservative measures fail. ${ }^{5}$

\section{SUMMARY}

This is a case report of a patient who developed headache in the early postpartum period. An incorrect assumption was made that the headache resulted from the epidural technique. As a result the diagnosis of intracerebral haemorrhage was missed until very late.

\section{RÉSUMÉ}

Une malade ayant présenté une céphalée peu après un accouchement, cette céphalée fut attribuée incorrectement à une anesthésie péridurale. Le diagnostic véritable d'hémorrhagie cérébrale fut manqué et ne fut fait que très tardivement.

Les leçons à tirer de cette observation sont dégagées.

\section{REFERENCES}

1. Wylie \& Churchill-Davidson A practice of anesthesia. 3rd ed. 1972. Year Book Medical Publishers, Chicago.

2. MacBryde, C.M. \& Blacklow, R.S. Signs \& symptoms, applied pathologic physiology and clinical interpretations. 5th ed. 1972. J.B. Lippincott Company, Toronto.

3. Vinken, P.J. \& BruYN, G.W. Headaches and clinical neuralgias. Handbook of Clinical Neurology, vol. 5. North-Holland Publishing Company, Amsterdam, 1968.

4. Wintrobe, et al. Harrison's principles of internal medicine. McGraw-Hill Book Company. 7 th ed. 1974 .

5. Epidural blood patch for post-lumbar headache. Anesthesiology 41 : 3, p. 307, Sept. 1974. 